\title{
Association of Probable Defective Phage Particles with Lysis by Bacteriophage AP50 in Bacillus anthracis
}

\author{
By ELISABETH NAGY AND G. IVÁNOVICS \\ Institute of Microbiology, Medical University, Szeged, Hungary
}

(Received 29 March 1977 ; revised 6 May 1977)

\begin{abstract}
INTRODUCTION
The main characteristics of a bacteriophage designated AP50 have been described previously (Nagy, 1974). This bacteriophage is unusual in its RNA and phospholipid content, and in its host specificity, the only sensitive species being Bacillus anthracis (Nagy, Prágai \& Ivánovics, 1976). Only about one-third of the isolates of this pathogen could propagate AP50. The aim of the present study was to define factors involved in the plaque formation of AP5o in individual strains of B. anthracis.
\end{abstract}

\section{METHODS}

Bacteria. The majority of the Bacillus anthracis strains were isolated from veterinary specimens in Hungary about 50 years ago and maintained as spore suspensions. Their identity was confirmed recently (Ivánovics \& Földes, 1958). These strains were fully virulent when first isolated, i.e. all were capsulogenic $\left(\mathrm{C}^{+}\right)$, but some of them have given rise to non-capsulogenic $\left(\mathrm{C}^{-}\right)$mutants. A number of $\mathrm{C}^{-}$mutants were obtained by the method of Sterne (1939) modified by Ivánovics (I962). Strains CNI 8-74 and CN35-I 8 were given by M. Sterne (Burroughs Wellcome, Beckenham, Kent), and strain Vollum and its non-proteolytic mutant, strain NPA, by H. Smith (University of Birmingham). Some isolates of B. anthracis Vollum $\mathrm{C}^{-}$harbouring a defective prophage (designated by serial numbers and $\mathrm{VC}^{-} d l$ ) were constructed (Ivánovics, 1967); these carry an incomplete genome of phage W (McCloy, 195I). A non-defective lysogenic isolate of strain Vollum $\mathrm{C}^{-}$was constructed by lysogenizing it with phage $\mathrm{W} \beta$; the isolate obtained was designated $\mathrm{VC}^{-}(\beta)$. Strain Davis received from E. Meynell (University of Kent, Canterbury) proved to be a sensitive host for most anthrax phages but not AP5o.

Phage AP50 and its assay. Phage AP50 was obtained as described by Nagy (1974). The lysate contained approximately $\mathrm{IO}^{10}$ p.f.u. $\mathrm{ml}^{-1}$ when assayed by an overlay technique with strain CNI 8-74. To test the sensitivities of the individual strains to AP5o, serial dilutions of the phage were spotted on to the surface lawn of the organisms. The highest decimal dilution forming plaques was taken as the degree of the sensitivity of the strain.

Media. These were YP broth (yeast extract, peptone; Csiszár \& Ivánovics, 1965) and YC (yeast extract, casein hydrolysate). The latter was used for detecting capsule production in a $\mathrm{CO}_{2}$ atmosphere (Ivánovics, 1962).

Induction of strains. YP medium ( $10 \mathrm{ml}$ ) in $100 \mathrm{ml}$ Erlenmeyer flasks was inoculated from an overnight broth culture and aerated by vigorous shaking in a water bath at $37^{\circ} \mathrm{C}$. The absorbance was measured by a Bausch \& Lomb Spectronic 20 photometer at $620 \mathrm{~nm}$. When the absorbance reached $0 \cdot 25$, mitomycin C (MC) was added to the culture which was then re-incubated. An MC concentration of $0.5 \mu \mathrm{g} \mathrm{ml}^{-1}$ caused lysis of most of the strains. When this MC concentration did not result in significant lysis within $4 \mathrm{~h}$, the procedure was repeated with $5 \mu \mathrm{g} \mathrm{MC} \mathrm{ml}^{-1}$. Each lysate was assayed for the presence of phage plaques with strain Davis.

Adsorption of AP5O. The rate of adsorption of AP5O was determined at $37^{\circ} \mathrm{C}$ by the method of Adams (1959). The period of adsorption was not extended beyond $30 \mathrm{~min}$ because of the possibility of phage propagation.

Electron microscopy of the lysates. Lysates of cultures of 200 to $300 \mathrm{ml}$ obtained by induction with MC were centrifuged and concentrated with polyethylene glycol (PEG) by the method of Yamamoto et al. (1970). The filtrates of the non-inducible strains were concentrated similarly. Concentrates were prepared for electron microscopy as described by Nagy \& Ivánovics (1972); the JEM $100 \mathrm{~B}$ electron microscope was operated at $80 \mathrm{kV}$. 
Table I. Characteristics of Bacillus anthracis strains

\begin{tabular}{|c|c|c|c|c|c|c|c|c|}
\hline \multirow[b]{3}{*}{ Group } & \multirow{3}{*}{$\begin{array}{c}\text { Strain } \\
\text { designation }\end{array}$} & \multirow{2}{*}{\multicolumn{2}{|c|}{$\begin{array}{l}\text { Sensitivity* } \\
\text { to AP50 at: }\end{array}$}} & \multirow{3}{*}{$\begin{array}{l}\text { Adsorption } \\
\text { of AP50 at } \\
37^{\circ} \mathrm{C}(\%)\end{array}$} & \multicolumn{3}{|c|}{ Induction by $\mathrm{MC}^{*}$} & \multirow{3}{*}{$\begin{array}{c}\text { Defective } \\
\text { phage in } \\
\text { lysate }\end{array}$} \\
\hline & & & & & \multicolumn{2}{|c|}{ Absorbance } & \multirow{2}{*}{$\frac{\text { Max. }}{\text { Min. }}$} & \\
\hline & & $26^{\circ} \mathrm{C}$ & $37^{\circ} \mathrm{C}$ & & & Min. & & \\
\hline \multirow[t]{13}{*}{ A } & CNI 8-74 & 8 & 8 & 85 & $1 \cdot 00$ & 0.40 & $2 \cdot 5$ & + \\
\hline & CN35-I 8 & 8 & 8 & 95 & 0.75 & $0 \cdot 15$ & $5 \cdot 0$ & + \\
\hline & $\mathrm{A} 68 \mathrm{C}^{-}$ & 6 & 6 & 79 & 0.95 & 0.32 & $3 \cdot 0$ & + \\
\hline & A7Ia $C^{+}$ & 6 & 6 & 57 & 0.84 & 0.34 & $2 \cdot 5$ & NT \\
\hline & A7Ia C - & 6 & 6 & 60 & 0.88 & 0.37 & $2 \cdot 3$ & + \\
\hline & $\mathrm{A} 78 \mathrm{C}^{-}$ & 6 & 6 & 70 & $I \cdot 00$ & 0.30 & $3 \cdot 3$ & + \\
\hline & $\mathrm{A} 8 \mathrm{I} \mathrm{C}^{+}$ & 6 & 6 & 63 & 0.90 & $0 \cdot 28$ & $3 \cdot 2$ & NT \\
\hline & A81 C - & 6 & 6 & 63 & 0.84 & 0.28 & $3 \cdot 0$ & + \\
\hline & A9I $\mathrm{C}^{+}$ & 5 & 5 & 59 & 0.68 & 0.08 & $8 \cdot 5$ & NT \\
\hline & A9I $C^{-}$ & 5 & 5 & 69 & 0.74 & 0.10 & $7 \cdot 4$ & + \\
\hline & $\mathrm{A} 92 \mathrm{C}^{+}$ & 6 & 6 & 70 & 0.85 & 0.25 & $3 \cdot 4$ & NT \\
\hline & $\mathrm{A} 92 \mathrm{C}^{-}$ & 6 & 6 & 72 & 0.82 & 0.28 & $3 \cdot 3$ & + \\
\hline & A96 C - & 6 & 6 & 70 & 0.80 & 0.10 & $8 \cdot 0$ & + \\
\hline \multirow[t]{6}{*}{ B } & $\mathrm{A}_{66} \mathrm{C}^{+}$ & 4 & 0 & 60 & 0.88 & 0.40 & $2 \cdot 2$ & + \\
\hline & $\mathrm{A} 72 \mathrm{C}^{+}$ & 6 & 0 & 83 & 0.82 & $0.3^{8}$ & $2 \cdot 1$ & + \\
\hline & A74a $C^{+}$ & 6 & 0 & 72 & 0.90 & 0.40 & $2 \cdot 2$ & + \\
\hline & A75 $\mathrm{C}^{+}$ & 3 & 0 & 77 & 0.80 & $0.3 \mathrm{I}$ & $2 \cdot 5$ & NT \\
\hline & A76 C + & 6 & 0 & $5 I$ & 0.92 & 0.41 & $2 \cdot 2$ & NT \\
\hline & A93 $\mathrm{C}^{+}$ & 4 & 0 & 34 & 0.89 & 0.40 & $2 \cdot 2$ & + \\
\hline \multirow[t]{7}{*}{$\mathrm{C}$} & Vollum $\mathrm{C}^{+}$ & 0 & o & o & 0.85 & 0.75 & $I \cdot I$ & NT \\
\hline & Vollum $\mathrm{C}^{-}$ & 0 & 0 & 0 & 0.80 & $0 \cdot 75$ & $1 \cdot 06$ & - \\
\hline & NPA $C^{-}$ & o & o & 0 & 0.65 & 0.52 & $\mathrm{I} \cdot 2$ & - \\
\hline & $\mathrm{A} 87 \mathrm{C}^{-}$ & 0 & 0 & 0 & $r \cdot 10$ & I $\cdot 00$ & $I \cdot I$ & - \\
\hline & $\mathrm{A}^{8} 8 \mathrm{C}^{+}$ & 0 & 0 & 0 & 0.65 & 0.58 & $I \cdot I$ & NT \\
\hline & A89 $C^{+}$ & 0 & 0 & 0 & 0.90 & 0.83 & I .08 & NT \\
\hline & A94 $\mathrm{C}^{+}$ & 0 & 0 & 0 & 0.85 & 0.78 & $\mathrm{I} \cdot 08$ & - \\
\hline \multirow[t]{6}{*}{$\mathrm{D}$} & ${ }_{5} \mathrm{VC}^{-} d l$ & 0 & 0 & 46 & to. 52 & 0.18 & $2 \cdot 9$ & + \\
\hline & $6 \mathrm{aVC}^{-} d l$ & 3 & 3 & 94 & to. 50 & 0.15 & $3 \cdot 3$ & $t$ \\
\hline & $6 \mathrm{bVC}^{-} d l$ & 0 & 0 & 50 & to. 42 & 0.10 & $4 \cdot 2$ & + \\
\hline & $7 \mathrm{VC}^{-} d l$ & 3 & 3 & 92 & to. 46 & 0.12 & $3 \cdot 8$ & + \\
\hline & $\mathrm{IOVC}^{-} d l$ & o & o & 43 & To. 50 & 0.07 & $7 \cdot 1$ & + \\
\hline & $\mathrm{IVC}^{-} d l$ & 3 & 3 & 95 & †०. 55 & 0.10 & $5 \cdot 5$ & + \\
\hline
\end{tabular}

\section{RESULTS AND DISCUSSION}

The strains tested, which included both wild-type $\mathrm{C}^{+}$and non-capsulogenic $\mathrm{C}^{-}$strains, were classified on the basis of their sensitivity to phage AP50 into four groups (Table I). Phage AP5o formed plaques on all strains of group A at both 26 and $37^{\circ} \mathrm{C}$. Included in this group were two isolates of Sterne (CNI8-74, CN35-I 8) which have been studied previously (Nagy \& Ivánovics, I972; Nagy, I974). Group B consisted of strains that were not able to propagate the phage at $37^{\circ} \mathrm{C}$ but gave plaques at $26^{\circ} \mathrm{C}$ after $48 \mathrm{~h}$, although these were very turbid. The strains belonging to group $\mathrm{C}$ did not plaque with $\mathrm{AP}_{50}$. The variation in the sensitivities of $\mathrm{C}^{+}$and $\mathrm{C}^{-}$strains could not be related to the genetic alleles of capsule production. Six defective lysogenic isolates comprised group $\mathrm{D}$, although there were marked differences between the sensitivities of the strains to phage AP5O. Three of them were moderately sensitive, while three did not propagate the phage; with the latter, the adsorption rate was between 43 and $50 \%$.

The groups exhibited definite differences in the adsorption of phage AP5O, in parallel with their phage sensitivities (Table $\mathrm{I}$ ). With group $\mathrm{C}$ the adsorption rate was always $0 \%$.

One lysogenic derivative of strain Vollum $\mathrm{C}^{-}\left[\mathrm{VC}^{-}(\beta)\right]$ was neither sensitive to phage AP50 nor capable of adsorbing it. This result suggested that normal prophage $\mathrm{W}(\beta)$ does 

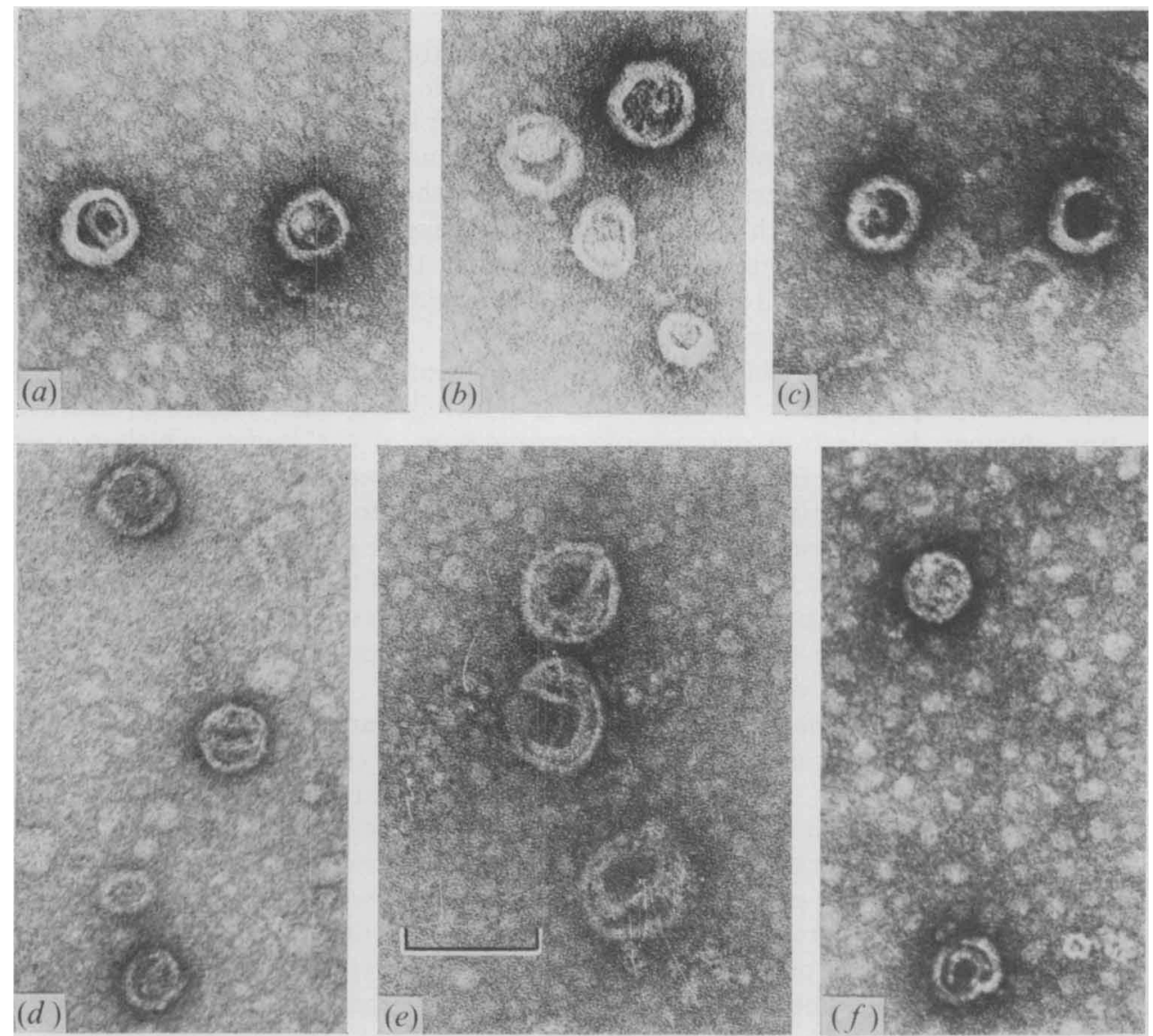

Fig. I. Electron micrographs of concentrated lysates of $B$. anthracis strains of group A [ $(a)$ A7ra $C^{-}$, (b) $\left.\mathrm{A} 8 \mathrm{I} \mathrm{C}^{-},(c) \mathrm{A} 9 \mathrm{I} \mathrm{C}^{-},(d) \mathrm{A}_{2} \mathrm{C}^{-}\right]$, group B $\left[(e) \mathrm{A}_{66} \mathrm{C}^{+}\right]$and group $\mathrm{D}\left[(f){ }_{7} \mathrm{VC}^{-} d l\right]$. Negative staining with $2 \%(\mathrm{w} / \mathrm{v})$ uranyl acetate. Bar marker represents $100 \mathrm{~nm}$.

not elicit receptor production corresponding to the sensitivity to $\mathrm{AP}_{50}$, but one or more of its fragments do (see group D).

When incubated in the presence of $M C$ the individual strains attained a maximum absorbance within 60 to $\mathrm{I} 20 \mathrm{~min}$, and thereafter the absorbance of the cultures dropped to a minimum at 240 min. This lysis was marked in group A, but was less evident in group B at an MC concentration of $0.5 \mu \mathrm{g} \mathrm{ml}^{-1}$. In order to express the induction of lysis of the strains numerically, the ratios of the maximum to minimum values of the growth curves were calculated (Table I). Addition of $0.5 \mu \mathrm{g} \mathrm{MC} \mathrm{ml}^{-1}$ elicited marked lysis in most strains of groups $A$ and $B$, but the values of this ratio varied considerably; the lowest was $2 \cdot I$ for strain $\mathrm{A}_{72} \mathrm{C}^{+}$. In spite of this, the lysis of this strain was estimated to be about $90 \%$ using a calibration curve (Nagy \& Ivánovics, 1972). For the members of group C, which were neither sensitive to phage AP50 nor capable of adsorbing it, the ratios were near $\mathrm{I} \cdot 0$. Thus, for Vollum $\mathrm{C}^{-}$the ratio indicated a cell decrease of only $10 \%$. In group $\mathrm{D}$, only an $\mathrm{MC}$ concentration of $5 \mu \mathrm{g} \mathrm{ml}^{-1}$ could elicit mass lysis. This was in accordance with the data described earlier by McCloy (1958) and Ivánovics (1967) who showed that lysogenic or defective lysogenic strains with phage $\mathrm{W}$ resist lysis by ultraviolet irradiation. In contrast, the strains of group $\mathrm{C}$ were not more liable to lysis when the $\mathrm{MC}$ concentration was increased. Thus, the slight decrease in absorbance following the peak shown by the strains of group $\mathrm{C}$ may be due to an aggregation of chain-formers or partial autolysis of bacteria, or both. 
Altogether 2I strains were selected for electron microscopic examination; 17 of these were inducible with MC. All lysates of the inducible strains tested contained structures resembling defective phage particles. In every preparation, round or partially-deformed empty bacteriophage heads were seen, varying in diameter from 53 to $80 \mathrm{~nm}$ (Fig. I). None of the lysates showed other morphological elements, such as tail-like structures or filaments. These electron microscope observations were similar to those for the lysates of the Sterne strains (CNI8-74, CN35-I8) which are very sensitive to phage AP5O, and which were previously also found to contain defective phage particles in their lysates (Nagy \& Ivánovics, 1972). None of the concentrated filtrates of the four strains belonging to group $\mathrm{C}$ showed any structures resembling defective phage particles.

All strains of $B$. anthracis which were able to propagate phage AP50 were thought to harbour a defective prophage on the basis of their inducibility by MC. Further evidence for this was obtained by electron microscopic examination of the lysates which revealed structures resembling phage fragments. Such a structure may well be helper genome for the multiplication of phage AP50. Strains artificially converted to be defective lysogens with phage W merit special interest since the origin of their defective genome is known. Although phage AP5o can be adsorbed by all of these strains only half of them were moderately sensitive, while the rest did not propagate $\mathrm{AP}_{50}$ at all. This suggests that the character of the gene fragments carried by the sensitive strains may be important in respect of their supporting the propagation of phage AP5o.

Lysogenic strains of $B$. anthracis liberating infective phage particles are not rare in nature. Buck et al. (1963) collected more than a hundred $B$. anthracis isolates from several laboratories and found that $18 \%$ liberated infective phages of varying host specificities. It is striking that in our material no lysogenic strains, but only defective lysogens were found. The proportion of the latter exceeded that of the lysogenic strains of Buck et al. (1963).

In other bacterial species phage genome is established as essential for the replication of bacteriophages. As early as $I_{96}$, the coli phage $P_{4}$ was discovered as a satellite, the propagation of which depended on prophage $\mathrm{P}_{2}$ as a helper (Six, 1963). When $\mathrm{M}_{13}$, a filiform coli phage undergoes propagation, a satellite or defective mini phage appears in the progeny; the length of this is one-fifth to one-half of that of the normal MI3 and it contains singlestranded DNA. The mini particles replicate only upon coinfection with normal Mi3 (Hewitt, 1975). Another example of cooperation of phage genomes is that which exists between phage mutant $T_{1}$ am 23 and $\lambda$. Phage $\lambda$ allows the replication of this amber mutant in a non-permissive host (Christensen, 1976). The propagation of RNA phage AP50 in $B$. anthracis may also depend on helper genome that is probably a defective phage fragment.

We thank the colleagues mentioned in Methods for the gift of bacterial and phage materials, and Miss Mária Fogas for skilled technical assistance.

\section{REFERENCES}

Adams, M. H. (1959). Bacteriophages. New York: Interscience.

Buck, C. A., Anacker, R. J., Newman, F. S. \& Eisenstark, A. (1963). Phage isolated from lysogenic Bacillus anthracis. Journal of Bacteriology 85, 1423-1430.

Christensen, J. R. (I976). Red system of bacteriophage complements the growth of bacteriophage $\mathrm{T}_{1}$ gene 4 mutant. Journal of Virology $\mathbf{1 7}_{7}, 7^{1} 3^{-}$ 717.

CsiszáR, K. \& Ivánovics, G. (1965). Transduction in Bacillus subtilis. Acta microbiologica Academiae scientiarum hungaricae 12, 72-89.
Hewitt, J. A. (I975). Miniphage - a class of satellite phages to MI3. Journal of General Virology 26, 87-94.

IvÁNOVICs, G. (I962). The pathogenicity of Bacillus anthracis lysogenic with mutants of phage W. Journal of General Microbiology 28, 87-101.

IvÁNovics, G. (1967). Defective lysogene Bacillus anthracis Stämme. Acta microbiologica Academiae scientiarum hungaricae 14, 71-75.

Ivánovics, G. \& FöldEs, J. (1958). Problems concerning the phylogenesis of Bacillus anthracis. Acta microbiologica Academiae scientiarum hungaricae 5, 89-109. 
McCloy, E. W. (I95I). Studies on a lysogenic Bacillus strain. I. A bacteriophage specific for Bacillus anthracis. Journal of Hygiene, Cambridge 49, II4-I 25.

MCCLoY, E. W. (1958). Lysogenicity and immunity to Bacillus phage W. Journal of General Microbiology 18, 198-220.

NAGY, E. (1974). A highly specific phage attacking Bacillus anthracis strain Sterne. Acta microbiologica Academiae scientiarum hungaricae 2r, 257-263.

NaGY, E. \& Ivánovics, G. (1972). Defective lysogeny in Bacillus anthracis Sterne strains. Acta microbiologica Academiae scientiarum hungaricae r9, 69-76.

Nagy, E., Prágai, B. \& Ivánovics, G. (1976).
Characteristics of phage AP5o, an RNA phage containing phospholipids. Journal of General Virology 32, I 29-I 32.

SIX, F. W. (1963). A defective phage depending on phage $\mathrm{P}_{2}$. Bacteriological Proceedings, $\mathbf{I} 38$.

STERNE, M. (1939). The use of anthrax vaccines prepared from avirulent uncapsulated variant of Bacillus anthracis. Onderstepoort Journal of Veterinary Science and Animal Industry 13, 3073 I 2.

Yamamoto, K. R., Alberts, B. M., Benzinger, R., LaWhorne, L. \& Treiber, G. (1970). Rapid bacteriophage sedimentation in the presence of polyethylene glycol and its application to largescale virus purification. Virology 40, 734-744. 